\title{
Circulative Oxidative Stress Indices and Ameliorative Potential of S-Adenosyl Methionine in Canine Sarcoptes Infestation
}

\author{
Ankur Upadhyay ${ }^{1}$, Mukesh Kumar Srivastava ${ }^{1}$, Amangeet Parashar ${ }^{1}$, P.N. Panigrahi ${ }^{1}$, Jaideep Singh ${ }^{1}$, \\ Vimlesh Kumar $^{2}$, Anil Singh ${ }^{2}$, Barkha Sharma ${ }^{1}$ and Shivani Rajoriya ${ }^{3}$ \\ ${ }^{1}$ Department of Veterinary Medicine, College of Veterinary Science E Animal Husbandry, DUVASU, Mathura, \\ Uttar Pradesh, INDIA \\ ${ }^{2}$ Department of Veterinary Surgery \& Radiology, College of Veterinary Science and Animal Husbandry, DUVASU, Mathura, \\ Uttar Pradesh, INDIA \\ ${ }^{3}$ College of Biotechnology, DUVASU, Mathura, Uttar Pradesh, INDIA \\ "Corresponding author: MK Srivastava; E-mail: drmukeshvetmed@rediffmail.com
}

Received: 13 July, 2020

Revised: 20 Oct., 2020

Accepted: 28 Oct., 2020

\begin{abstract}
Present study describes the rhythm of oxidant/antioxidant status of dogs affected with sarcoptic mange and ameliorative effects of antioxidant (S-Adenosyl Methionine) supplementation on oxidant/antioxidant status of dogs affected with sarcoptic mange. Study was undertaken on twelve client owned dogs presented at TVCC, DUVASU, Mathura, confirmed to be suffering from sarcoptic mange, which were randomly divided in two groups (group 1 and 2) irrespective of age, sex and breed, comprising of six dogs each, while six healthy dogs were taken as control. Group 1 dogs were treated with only Doramectin @ $0.4 \mathrm{mg} /$ $\mathrm{kg}$ body weight subcutaneous weekly for 5 treatments along with standard treatment of pyoderma, whereas group 2 were additionally given S-adenosylmethionine (SAMe) @ $20 \mathrm{mg} / \mathrm{kg}$ body weight orally for 28 days. In the present investigation dogs with sarcoptic mange were found in a state of oxidative stress as indicated by significantly elevated Total Oxidant Status (TOS) and Oxidative Stress Index (OSI) values and significantly reduced Total Antioxidant Capacity (T-AOC) values as compared to healthy dogs. The dogs of group 2 showed better clinical recovery and marked ameliorations in TOS, T-AOC and OSI values in comparison to group 1 at the end of therapy. On the basis of findings of present investigation, it is concluded that administration of SAMe in addition to standard therapy can mitigate these alterations expediting the clinical recovery of diseased dogs and therefore can be recommended as an adjunct therapy with miticides for management of canine sarcoptic mange.
\end{abstract}

\section{HIGHLIGHTS}

0 Significantly elevated total oxidant status and oxidative stress index and significantly reduced total antioxidant capacity values.

(0 Administration of S-adenosylmethionine in addition to standard therapy can be recommended as an adjunct therapy in canine sarcoptic mange.

Keywords: Oxidative stress, S-Adenosyl Methionine, Sarcoptes, Canine

Oxidative stress arises either due to excess production of free radicals, or inadequate availability of antioxidants or a combination of both. Oxidative stress supervenes when generated free radicals exceeds the capacity of antioxidant defence of the body (Santra et al., 2000). Various substances known as reactive oxygen species (ROS) are constantly generated in vivo as an integral part of metabolism, as part of controlled inflammatory reactions and by exposure to environmental factors (Nemec et al., 2000). Estimation of antioxidant enzymes activities and levels of endogenous antioxidants in blood are indirect but reliable methods for

How to cite this article: Upadhyay, A., Srivastava, M.K., Parashar, A. Panigrahi, P.N., Singh, J., Kumar, V., Singh, A., Sharma, B. and Rajoriya, S. (2020). Circulative oxidative stress indices and ameliorative potentia of S-Adenosyl methionine in Canine Sarcoptes infestation. J. Anim. Res. 10(6): 907-916.

Source of Support: None; Conflict of Interest: None

(ब) 9 
assessment of free radicals activity and oxidative stress (Fang et al., 2002). Several available reports document compromise in endogenous antioxidant defence and increase in peroxidation products in blood indicating role of free radicals and oxidative stress in various infectious and inflammatory diseases in farm animals (Ranjan et al., 2005; Ranjan et al., 2006). In recent years there has been growing interest in understanding the role of free radicals in many diseases such as cancer, arteriosclerosis, aging, and parasitic infestation due to elevation of ROS or insufficient ROS detoxification and their prevention by antioxidants (Finkel and Holbrook, 2000).

Skin is considered as the mirror of health as there are numerous systemic states/diseases that may clinically be reflected by some skin abnormalities (Sharma et al., 2009). Amidst these skin problems, genus Sarcopteshas a very broad host range, including more than 100 mammalian species belonging to 27 families and ten orders (Bornstein et al., 2001; Pence and Ueckermann, 2002). Canine scabies (sarcoptic mange) is a highly contagious, intensely pruritic and potentially zoonotic skin condition caused by infestation of the skin by the mite, Sarcoptesscabiei var. canis (Anita and Peter, 2008), which burrows into its hosts`epidermis. Mechanical disruption and ingestion of cells and tissue fluids by the mites in the skin contribute to the pathogenesis of sarcoptic mange (Pence and Uckermann, 2002). Disease is characterized by severe pruritic papular eruptions, pinpoint crusts in combination with alopecia (Yathiraj et al., 1990; Pin et al., 2006) lead by secondary self-inflicted traumatic excoriations. Several studies exhibited that a variety of inflammatory cells are activated which induce or activate various oxidantgenerating enzymes to kill intra-cellular and extra-cellular parasites (Kocyigit et al., 2005). S. scabiei infestation is often followed by proliferation of mast cells and resultant increase in chymase and tryptase activity is supposed to play an important role in development of skin lesions (Noviana et al., 2004). It is known that inflammatory cells are increased as a result of inflammation in animals with mange; recruited neutrophils and macrophages produce reactive oxidants such as hydrogen peroxide, hypochlorite and oxygen radicals, and these reactive oxygen substances produced by cells of immune system show potent cytotoxic effects on parasites and as well as other pathogenic organisms. ROS trigger induction and maintenance of cutaneous inflammation (Trenam et al., 1992). To minimize oxidative damage, organisms developed antioxidative mechanisms triggered by an increased ROS production. The free radicals play a key role in host defence against the invading parasite (Hicks and Elston, 2009), but when generated at high levels they can result in metabolic dysfunction and biomolecular oxidative damage, which contribute to pathological changes in the tissues (Trouba et al., 2002; Valko et al., 2007). Oxidants such as ROS are balanced against this antioxidative defence system that consists of enzymes and metabolites in all subcellular compartments (Halliwell, 2006). This oxidative stress is mostly in the form of damage to lipids, DNA, carbohydrates and proteins (Bargaglia et al., 2009). Response of individual against detrimental consequences of free radicals is through antioxidant defence system, comprising of antioxidant enzymes, like Superoxide dismutase (SOD), catalase (CAT), glutathione peroxidase (GSH-Px), and glutathione reductase; endogenous antioxidants, such as GSH and ubiquinone and nutritional antioxidants such as vitamins $\mathrm{C}$ and $\mathrm{E}$, zinc, folate, selenium, and carotenoids.

$\mathrm{S}$-Adenosylmethionine (SAMe) is a co-substrate formed naturally by healthy liver and involved in production of glutathione - an essential antioxidant that protects liver cells, detoxifies liver, enhances immune system, and neutralizes damaging elements called free radicals. S-adenosylmethionine (SAMe) is generated from L-methionine and ATP in a two-step reaction catalysed by methionine adenosyltransferase (MAT) (Mato and Lu, 2007; Hanje et al., 2006).

Macrocyclic lactones (MLs) are a large family of broadspectrum antiparasitic drugs widely used for the treatment of arthropods and nematodes parasites in veterinary and human medicine (Hennessy and Alvinerie, 2002) and includes two distinct chemical families milbemycins and avermectins. Doramectin a novel avermectin produced by fermentation of Streptomyces avermitilis, has a wide antihelmenthic and ectoparasiticidal spectrum of activity (Goudie et al., 1993). It is approved for use in domestic animals at the dosage of $0.2 \mathrm{mg} \mathrm{kg}^{-1}$ of bodyweight (Logan et al., 1993; Reinmeyer and Courteny, 2001). Hence, the present study was conducted to determine the alteration in circulative oxidative stress indices as well as to estimate ameliorative potential of S-Adenosyl Methionine along with doramectin in canine sarcoptes infestation. 


\section{MATERIALS AND METHODS}

\section{Ethical approval}

The guidelines for animal experimentation followed in this study was approved by Institutional Animal Ethics Committee and the ethical guidelines of UP Pt. Deen Dayal Upadhyaya Pashu Chikitsa Vigyan Viswavidyalaya evam Go-Anusandhan Sansthan (DUVASU), Mathura were followed during all the experiments.

\section{Selection of dogs}

The present study was undertaken on twelve client owned dogs confirmed to be suffering from sarcoptic mange irrespective of age, sex and breed presented at TVCC, DUVASU, Mathura, while six healthy dogs were taken as control. The most prominent clinical signs observed were persistent and intense pruritus, alopecia, crust formations, excoriations and irritability in all clinical cases. The lesions were observed on head, pinnae, legs (elbows and hocks) and ventrum. Confirmatory diagnosis of sarcoptic mange was based on the presence of Sarcoptes scabiei mites or mites with their developmental stages on microscopic examination of skin scrapping material. Faecal samples were negative for eggs of internal parasites and dogs were free from any concurrent disease in study group.

\section{Blood sample collection}

With the informed oral assent of the dog owners, about $5 \mathrm{ml}$ of blood from each diseased dog was collected from the recurrent tarsal or radial vein using disposable syringe and needle. Blood samples were acquired from all exploratory canines on days 0,14 and 28 during the study period. Blood was taken in plane vials without any anticoagulant and the vials were kept in a slanted position for 25-30 minutes at normal room temperature, followed by subjected to be centrifuged @2000 rpm for 5 minutes for harvesting of serum for the study of biochemical panels, total antioxidant capacity and total oxidant status. Similarly, blood samples were also procured from the healthy dogs and were used as reference value (Control Group).

\section{Mite counts}

For parasitological examination, a dulled scalpel blade was held perpendicular to the skin and used with modest pressure to scrape in the direction of hair growth. Skin scraping samples of $5 \mathrm{~cm} \times 5 \mathrm{~cm}$ were taken from five affected sites. Scraping samples of the dogs from the study group were transferred into test tube, and 2-3 $\mathrm{ml}$ of $10 \%$ $\mathrm{KOH}$ was added; samples were mildly heated over spirit lamp until for 1-2 bumps were seen and then centrifuged on $1500 \mathrm{rpm}$ for $5 \mathrm{~min}$. Obtained precipitates were examined under microscope, and mites were identified according to morphological features. The average mite count was determined by averaging the mite count from five fields and was performed on days 0,14 and 28 to assess the laboratory-based recovery (Parasitological cure).

\section{Clinical recovery score analysis}

For assessment of clinical recovery seven clinical symptoms (pruritus, erythema, papules, excoriations, crusts (scabs), alopecia and pyoderma lesions) were assessed and rated on a scale from absent (0) to severe (3). The seven scores were added up and expressed as a Sarcoptes-induced skin lesions score (SSLS) that could have values between 0 and 21 (Krieger et al., 2005). Percent clinical recovery was calculated by using formula e.g., $\%$ Clinical recovery $=[($ Day 0 SSLS - SSLS at day post therapy) / Day 0 SSLS] $\times 100$.

\section{Assay of canine total oxidant status (TOS) and canine total antioxidant capacity (T-AOC)}

The Biocodon Sandwich Elisa kits were used for quantitative estimation of canine total oxidant status (TOS) and canine total antioxidant capacity (T-AOC) following manufactures guidelines. The TOS to T-AOCratio was regarded as the OSI which was analysed as per method suggested by Camkerten et al. (2009).

\section{Treatment plan}

The dogs affected with sarcoptic acariasis were allocated into two groups, each comprises of six dogs and the design of study was as follows:

Treatment Group 1: Dogs with sarcoptic acariasis were treated with Inj. Doramectin @ $0.4 \mathrm{mg} / \mathrm{kg}$ body weight subcutaneous every week for 5 treatments (Tilley et al., 2007) along with standard treatment of pyoderma if 
any with Tab. Cephalexin @ 15-20 mg/kg body weight orally twice daily for 7-10 days and Shampoo containing chlorhexidine gluconate $2.1 \%$ and ketoconazole $1 \%$ applied at weekly intervals.

Treatment Group 2: Dogs with sarcoptic acariasis were treated with Inj. Doramectin @ $0.4 \mathrm{mg} / \mathrm{kg}$ body weight subcutaneous every week for 5 treatments (Tilley et al., 2007) along with Tab. S-adenosylmethionine (SAMe) (a) $20 \mathrm{mg} / \mathrm{kg}$ body weight orally once daily for 28 days. (Webster and Cooper, 2009). Additionally, standard treatment of pyoderma if any similar to group 1 .

Control Group: Comprised of minimum six healthy dogs of any age, breed and sex. Healthy status was confirmed by thorough clinical examination and application of same laboratory tests, which were utilized for treatment group.

\section{Statistical analysis}

The values of various parameters were expressed as mean \pm S.E. and Data were analysed by one-way (ANOVA) Analysis of Variance followed by the Post-Hoc tukey HSD test using Statistical Package for the Social Sciences (SPSS 16.0). The level of statistical significance for all comparisons was established at $(\mathrm{P}<0.05)$.

\section{RESULTS AND DISCUSSION}

In present study the most prominent and characteristics signs observed were persistent and intense pruritus, alopecia, crust formations, excoriations and irritability in all 12 clinical cases suffering from sarcoptic mange. The pinnal-pedal scratch reflex was found to be positive in $75 \%$ of sarcoptes infested dogs. Bourdeau et al. (2004) reported that approximately $50 \%$ of scabetic dogs have a positive pinnal-pedal reflex, while others showed rates between $75 \%$ and $90 \%$ (Griffin, 1993; Mueller et al., 2001). Keratinization was noticed in about $50 \%$ cases and erythema was found in most of the dogs. Typically, lesions were observed on the head and the pinnae, the legs (particularly the elbows and the hocks) and the ventrum.

\section{Serum biochemistry}

Biochemical parameters of healthy dogs and dogs suffering from Canine Sarcoptic Acariasis are depicted in Table 1-4. The mean values of biochemical parameters viz. aspartate aminotransferase (AST), alanine aminotransferase (ALT) were significantly higher in scabetic dogs than in control while glucose, cholesterol, total protein, albumin, albumin/globulin ratio and blood urea nitrogen showed significantly lower mean values in scabetic dogs than in control. Significant amelioration in various biochemical parameters were recorded on day 28 post therapy in the treatment group. However, biochemical parameters like AST, ALT and cholesterol levels could not attain comparable values to that of healthy controls at day 28 post therapy in treatment group 1 while treatment group 2 revealed remarkable amelioration in these panels on day 28 post therapy which could be attributed to ameliorative potentials of SAMe in this group.

In the present study the mean blood glucose levels in sarcoptic dogs was significantly lower than in control indicating hypoglycaemia, which is in agreement with previous findings (Sakina and Mandial, 2013; Narang et al., 2015; Beigh et al., 2016). Hypoglycaemia in scabies might be due to increased need of skin, during inflammatory reactions for glucose (Sharma, 2006). The serum glucose level in both the diseased group increased towards normalcy at day 28 post therapy. The mean serum cholesterol levels in sarcoptic dogs was significantly lower than in control. Similarly, Beigh et al. (2016) reported decreased cholesterol level in severely scabies-infected dogs which could be attributed to decreased synthesis by the liver. The estimated panels in group 2 attained comparable values to that of healthy controls at day 28 post therapy which could be due to the ameliorative effects of SAMe supplementation on liver.

A significant decrease in mean serum total protein level in sarcoptic dogs as compared to the healthy group indicated hypoproteinaemia, which was in agreement with the observations of Solanki et al. (2007) and Sakina and Mandial (2013). A significant decrease in mean serum albumin level in sarcoptic dogs as compared to the healthy group indicated hypoalbuminemia. Similar findings of reduced total protein and albumin were also reported by Lodh et al. (2012) and Reddy et al. (2014) in their study. A significant decrease in albumin-globulin ratio level in sarcoptic dogs as compared to the healthy group was also noticed in our study similar to findings of Behera et al. (2011). In the present study, lower albumin level would have resulted in decreased total protein and $\mathrm{A} / \mathrm{G}$ ratio. Present findings were in agreement with the 
earlier findings of decreased total protein and albumin in canine scabies (Chandy et al., 2000) and sarcoptic mange in sheep (Hirudkar et al., 1997). As the reduction in total serum protein was observed in affected dogs because albumin that is released leading to hypoproteinemia condition and that may be due to burrowing nature of the mite leading to leaching of protein fractions from the body fluids (Benjamin, 1978). In the present study the decreased albumin levels might either be due to malnutrition or parasitism which sufficiently showed that scabies affects feed conversion efficiency and growth weights. Decrease in albumin levels might be attributed to continuous loss of plasma protein through internal bleeding and subsequent haemodilution as a result of mobilization of fluid from pruritis which attributed to hypoalbuminemia (Benjamin, 1978). The estimated panels of total protein and albumin in both the treatment groups achieved a comparable value to that of healthy animals at day 28 post therapy. In the present study nonsignificant difference in mean serum globulin level in sarcoptic dogs was recorded as compared to the healthy group, which is in agreement with the findings of Lodh et al. (2012). However, Sakina and Mandial (2013) and Beigh et al. (2016) recorded hyperglobinemia in sarcoptic infested dogs.

In the present study the mean aspartate transferees (AST) andalanine tranferese (ALT) levels in sarcoptic dogs was significantly higher than in control. Similarly, Beigh et al. (2016) reported elevated AST \& ALT level in severely scabies-infected dogs which points toward compromised liver functions. Elevated levels of ALT, AST and decreased levels of albumin, glucose and cholesterol points toward compromised liver functions in severely scabies-infected dogs. As liver is the main organ for glycogenolysis, gluconeogenesis and for albumin and cholesterol synthesis decreased glucose, albumin and cholesterol concentration observed could be attributed to decreased synthesis by the liver. Similar changes in biochemical parameters have also been observed in sarcoptic mange affected goats (De and Dey, 2010) and dogs (Sharma et al., 2011). During infestation the $S$. scabiei mite burrows in the stratum corneum of the skin and resides within the skin of the host during entire life cycle process (Willis et al., 2006). As the infestation progresses, the number of mites increases in the skin and it releases sufficient antigenic material which are able to increase pro-inflammatory cytokines level in blood and skin cells (Arlian et al., 2003; Mullins et al., 2009) and the pro-inflammatory cytokines such as tumor necrosis factor-alpha (TNF- $\alpha$ ) and other cytokines have been found to play a significant role in the onset of liver disease (Thurman et al., 1999). Thus, the probable cause of liver dysfunction could be due to adverse effects of pro-inflammatory cytokines and/or secretion of some toxins by mites that affects the vital organs. The estimated panels of AST and ALT values in group 2 attained comparable values to that of healthy controls at day 28 post therapy which could be attributed to the effects of S-Adenosylmethionine, which is an essential antioxidant that protects liver cells, detoxifies liver, enhances immune system, and neutralizes damaging elements called free radicals.

In present study significantly decreased BUN values were recorded at day $0 \& 14$ in diseased dogs as compared to the values of healthy dogs, while no significant changes were observed in creatinine values. Allaam et al. (2014) reported significantly low urea and creatinine in Egyptian Buffaloes (Bubalus bubalis) infested by sarcoptic mangeand attributed that decrease of urea should be linked with loss of appetite. The estimated panels attained comparable values to that of healthy controls at day 28 post therapy in both the treatment groups.

\section{Total oxidant status (TOS), total antioxidant capacity (T-AOC) and oxidative stress index (OSI)}

Apart from dermatological symptoms, scabies infection is also associated with physiological changes and oxidative stress is an important indicator to adjudge the degree of tissue damage in host system and it plays an important role in aetio-pathogenesis of various infectious, inflammatory and degenerative diseases (Ewans and Halliwell, 2001), including sarcoptic dermatitis (Saleh et al., 2010; Beigh et al., 2013b). Total Oxidant Status (TOS), Total Antioxidant Capacity (T-AOC) and Oxidative Stress Index (OSI) of healthy dogs and dogs suffering from Canine Sarcoptic Acariasis are depicted in Table 5.

In the present investigation dogs with sarcoptic mange were found in a state of oxidative stress as indicated by significantly elevated concentration of Total oxidant status (TOS) and Oxidative Stress Index (OSI) and significantly reduced concentration of Total antioxidant capacity (T-AOC) as compared to healthy dogs. In present study TOS and OSI values in group 2 attains comparable values 
Table 1: Alteration in serum glucose, cholesterol and triglyceride of healthy dogs and dogs suffering from Canine Sarcoptic Acariasis.

\begin{tabular}{|c|c|c|c|c|c|c|c|c|c|}
\hline \multirow{2}{*}{ Groups } & \multicolumn{3}{|c|}{ Glucose(mg/dL) } & \multicolumn{3}{|c|}{ Cholesterol (mg/dL) } & \multicolumn{3}{|c|}{ Triglyceride (mg/dL) } \\
\hline & DAY 0 & DAY 14 & & & DAY 14 & DAY 28 & DAY 0 & & DAY 28 \\
\hline & & $.50 \pm 2.99^{b}$ & $7066+29$ & $222.83 \pm 1$ & $222.66 \pm 11.20^{\mathrm{b}}$ & $222.83 \pm 12.09^{\mathrm{b}}$ & $53.83 \pm 5.32$ & \pm 4.71 & $0 \pm 4.9$ \\
\hline 1 & $46.83 \pm 1.57^{\mathrm{aA}}$ & $57.66 \pm 2.20^{\mathrm{aB}}$ & $68.83 \pm 2.79^{\mathrm{C}}$ & $164.50 \pm 5.15^{\mathrm{a}}$ & $171.33 \pm 4.16^{\mathrm{a}}$ & $174.16 \pm 4.21^{\mathrm{a}}$ & $48.50 \pm 5.34$ & $56.83 \pm 8.21$ & $61.50 \pm 6.71$ \\
\hline 2 & $47.66 \pm 2.96^{\mathrm{aA}}$ & $58.33 \pm 2.66^{\mathrm{aB}}$ & $69.33 \pm 2.65^{\mathrm{C}}$ & $164 \pm 6.59^{\mathrm{aA}}$ & $190.50 \pm 5.03^{\mathrm{aB}}$ & $220.66 \pm 9.18^{\mathrm{bC}}$ & $48.00 \pm 5.47$ & $55.83 \pm 8.79$ & $62.16 \pm 7.61$ \\
\hline
\end{tabular}

Mean with different superscript $(a, b, c)$ in columns are differing significantly in between the groups, otherwise non-significant.

Mean with different superscript (A, B, C) in rows are differing significantly in between the intervals, otherwise non-significant.

Table 2: Alteration in serum total protein, albumin and globulin of healthy dogs and dogs suffering from Canine Sarcoptic Acariasis

\begin{tabular}{llllllllll}
\hline \multirow{2}{*}{ Groups } & \multicolumn{3}{c}{ Total protein $(\mathbf{g m} / \mathbf{d L})$} & \multicolumn{3}{c}{ Albumin $(\mathbf{g m} / \mathbf{d L})$} & \multicolumn{3}{c}{ Globulin (gm/dL) } \\
\cline { 2 - 10 } & DAY 0 & DAY 14 & DAY 28 & DAY 0 & DAY 14 & DAY 28 & DAY 0 & DAY14 & DAY 28 \\
\hline Healthy & $6.06 \pm 0.06^{\mathrm{b}}$ & $6.08 \pm 0.06^{\mathrm{b}}$ & $6.10 \pm 0.05$ & $3.21 \pm 0.06^{\mathrm{b}}$ & $3.25 \pm 0.05^{\mathrm{b}}$ & $3.26 \pm 0.06$ & $2.85 \pm 0.03$ & $2.81 \pm 0.03$ & $2.83 \pm 0.03$ \\
Gr1 & $4.46 \pm 0.11^{\mathrm{aA}}$ & $5.01 \pm 0.04^{\mathrm{aB}}$ & $5.95 \pm 0.03^{\mathrm{C}}$ & $1.70 \pm 0.06^{\mathrm{aA}}$ & $2.35 \pm 0.03^{\mathrm{aB}}$ & $3.13 \pm 0.04^{\mathrm{C}}$ & $2.76 \pm 0.06$ & $2.76 \pm 0.05$ & $2.81 \pm 0.03$ \\
Gr2 & $4.45 \pm 0.08^{\mathrm{aA}}$ & $4.85 \pm 0.16^{\mathrm{aB}}$ & $5.98 \pm 0.06^{\mathrm{C}}$ & $1.68 \pm 0.04^{\mathrm{aA}}$ & $2.16 \pm 0.10^{\mathrm{aB}}$ & $3.15 \pm 0.04^{\mathrm{C}}$ & $2.76 \pm 0.04$ & $2.68 \pm 0.07$ & $2.83 \pm 0.03$ \\
\hline
\end{tabular}

Mean with different superscript $(a, b, c)$ in columns are differing significantly in between the groups, otherwise non-significant. Mean with different superscript $(A, B, C)$ in rows are differing significantly in between the intervals, otherwise non-significant.

Table 3: Alteration in serum A/G ratio, AST and ALT of healthy dogs and dogs suffering from Canine Sarcoptic Acariasis

\begin{tabular}{llllllllll}
\hline \multirow{2}{*}{ Groups } & \multicolumn{3}{c}{ A/G ratio } & \multicolumn{3}{c}{ AST $(\boldsymbol{\mu} / \mathbf{L})$} & \multicolumn{3}{c}{ ALT $(\boldsymbol{\mu} / \mathbf{L})$} \\
\cline { 2 - 9 } & DAY 0 & DAY 14 & DAY 28 & DAY 0 & DAY 14 & DAY 28 & DAY 0 & DAY 14 & DAY 28 \\
\hline Healthy & $1.12 \pm 0.02^{\mathrm{b}}$ & $1.13 \pm 0.03^{\mathrm{b}}$ & $1.15 \pm 0.03$ & $21.49 \pm 1.20^{\mathrm{a}}$ & $21.72 \pm 1.43^{\mathrm{a}}$ & $21.84 \pm 1.66^{\mathrm{a}}$ & $28.33 \pm 3.72^{\mathrm{a}}$ & $28.43 \pm 2.65^{\mathrm{a}}$ & $28.18 \pm 3.09^{\mathrm{a}}$ \\
Gr1 & $0.64 \pm 0.04^{\mathrm{aA}}$ & $0.84 \pm 0.00^{\mathrm{aB}}$ & $1.10 \pm 0.02^{\mathrm{C}}$ & $30.14 \pm 0.60^{\mathrm{b}}$ & $29.07 \pm 0.49^{\mathrm{c}}$ & $28.66 \pm 0.57^{\mathrm{b}}$ & $38.01 \pm 1.02^{\mathrm{b}}$ & $36.66 \pm 0.97^{\mathrm{b}}$ & $35.15 \pm 0.83^{\mathrm{b}}$ \\
Gr2 & $0.64 \pm 0.03^{\mathrm{aA}}$ & $0.80 \pm 0.02^{\mathrm{aB}}$ & $1.10 \pm 0.01^{\mathrm{C}}$ & $30.00 \pm 0.30^{\mathrm{bC}}$ & $25.67 \pm 0.22^{\mathrm{bB}}$ & $21.96 \pm 0.19^{\mathrm{aA}}$ & $38.16 \pm 1.16^{\mathrm{bC}}$ & $34.08 \pm 0.84^{\mathrm{abB}}$ & $28.88 \pm 0.50^{\mathrm{aA}}$ \\
\hline
\end{tabular}

Mean with different superscript $(a, b, c)$ in columns are differing significantly in between the groups, otherwise non-significant. Mean with different superscript (A, B, C) in rows are differing significantly in between the intervals, otherwise non-significant.

Table 4: Alteration in serum BUN, ALP and creatinine of healthy dogs and dogs suffering from Canine Sarcoptic Acariasis

\begin{tabular}{llllllllll}
\hline \multirow{2}{*}{ Groups } & \multicolumn{3}{c}{ BUN (mg/dL) } & \multicolumn{3}{c}{ ALP $(\boldsymbol{\mu} / \mathbf{L})$} & \multicolumn{3}{c}{ CREATININE (mg/dL) } \\
\cline { 2 - 11 } & DAY 0 & DAY 14 & DAY 28 & DAY 0 & DAY 14 & DAY 28 & DAY 0 & DAY 14 & DAY 28 \\
\hline Healthy & $14.13 \pm 0.43^{\mathrm{b}}$ & $14.66 \pm 0.35^{\mathrm{b}}$ & $14.08 \pm 0.39$ & $98.16 \pm 19.29$ & $98.50 \pm 18.99$ & $98.66 \pm 18.75$ & $0.59 \pm 0.02$ & $0.57 \pm 0.02$ & $0.58 \pm 0.03$ \\
Gr1 & $12.21 \pm 0.41^{\mathrm{a}}$ & $13.16 \pm 0.36^{\mathrm{a}}$ & $13.50 \pm 0.32$ & $93.83 \pm 29.38$ & $97.16 \pm 16.71$ & $96.66 \pm 17.47$ & $0.52 \pm 0.12$ & $0.48 \pm 0.06$ & $0.58 \pm 0.06$ \\
Gr2 & $12.50 \pm 0.40^{\mathrm{a}}$ & $13.20 \pm 0.40^{\mathrm{a}}$ & $13.66 \pm 0.24$ & $93.66 \pm 32.88$ & $98.83 \pm 18.21$ & $96.50 \pm 17.25$ & $0.50 \pm 0.12$ & $0.46 \pm 0.06$ & $0.54 \pm 0.02$ \\
\hline
\end{tabular}

Mean with different superscript $(a, b, c)$ in columns are differing significantly in between the groups, otherwise non-significant. Mean with different superscript (A, B, C) in rows are differing significantly in between the intervals, otherwise non-significant.

Table 5: Total oxidant status (TOS), total antioxidant capacity (T-AOC) and oxidative stress index (OSI) of healthy dogs and dogs suffering from Canine Sarcoptic Acariasis

\begin{tabular}{llllllllll}
\hline \multirow{2}{*}{ Groups } & \multicolumn{3}{c}{ TOS $(\mathbf{p g} / \mathbf{m l})$} & \multicolumn{3}{c}{ T-AOC (U/mI) } & \multicolumn{1}{c}{ OSI } \\
\cline { 2 - 9 } & DAY 0 & DAY 14 & DAY 28 & DAY 0 & DAY 14 & DAY 28 & DAY 0 & DAY 14 & DAY 28 \\
\hline Healthy & $13.30 \pm 0.42^{\mathrm{a}}$ & $13.15 \pm 0.38^{\mathrm{a}}$ & $13.33 \pm 0.40^{\mathrm{a}}$ & $5.13 \pm 0.35^{\mathrm{b}}$ & $5.16 \pm 0.25^{\mathrm{b}}$ & $5.14 \pm 0.22^{\mathrm{b}}$ & $2.63 \pm 0.15^{\mathrm{a}}$ & $2.56 \pm 0.12^{\mathrm{a}}$ & $2.6 \pm 0.09^{\mathrm{a}}$ \\
Gr1 & $42.63 \pm 2.29^{\mathrm{bB}}$ & $36.32 \pm 1.60^{\mathrm{cAB}}$ & $26.74 \pm 1.49^{\mathrm{bA}}$ & $2.59 \pm 0.17^{\mathrm{aA}}$ & $2.91 \pm 0.21^{\mathrm{aAB}}$ & $3.51 \pm 0.13^{\mathrm{aB}}$ & $16.95 \pm 1.72^{\mathrm{bB}}$ & $12.96 \pm 0.93^{\mathrm{cB}}$ & $7.69 \pm 0.65^{\mathrm{bA}}$ \\
Gr2 & $43.19 \pm 2.55^{\mathrm{bC}}$ & $26.04 \pm 1.47^{\mathrm{bB}}$ & $14.72 \pm 0.99^{\mathrm{aA}}$ & $2.54 \pm 0.14^{\mathrm{aA}}$ & $5.04 \pm 0.12^{\mathrm{bB}}$ & $7.11 \pm 0.29^{\mathrm{cC}}$ & $17.18 \pm 1.32^{\mathrm{bC}}$ & $5.18 \pm 0.34^{\mathrm{bB}}$ & $2.09 \pm 0.18^{\mathrm{aA}}$ \\
\hline
\end{tabular}

Mean with different superscript $(a, b, c)$ in columns are differing significantly in between the groups, otherwise non-significant. Mean with different superscript (A, B, C) in rows are differing significantly in between the intervals, otherwise non-significant. 
to that of healthy controls at day 28 post therapy and even a significantly increased value of T-AOCthan that of healthy controls at day 28 post therapy was observed. This condition could be attributed to the ameliorative/ antioxidant effect of S-Adenosylmethionine (SAMe) supplementation in this group. S-Adenosylmethionine (SAMe) is a co-substrate formed naturally by healthy liver and involved in production of glutathione which is an essential antioxidant that protects liver cells, detoxifies liver, enhances immune system, and neutralizes damaging elements called free radicals. Ara et al. (2008) reported that reactive oxygen and nitrogen species inactivate methionine adenosyltransferase (MAT) secondary to oxidation or nitrosylation of a cysteine residue on the enzyme. SAMe is involved in synthesis and metabolism of several vital compounds, such as phospholipids, nucleic acids, methylaccepting proteins, hormones and neurotransmitters through its transmethylation reactions. In intracellular trans-sulphuration pathway, SAMe represents an important precursor of cysteine, taurine and glutathione (GSH), the major intracellular antioxidant. SAMe increases the intracellular availability of cysteine, it increases hepatic GSH levels and has antioxidant activity. (Lieber, 2002; Martinez et al., 2002; Avila et al., 2002; Hanje et al., 2006). Several studies have demonstrated that SAMe can alleviate signs of oxidative and nitrosative stress (Lieber, 2002; Hanje et al., 2006). The cytoprotective benefits of SAMe in hepatobiliary disease include augmentation of hepatocyte GSH levels, improvement in membrane fluidity, modification of cytokine expression, alterations in DNA/histone methylation and modulation of apoptosis (Mato and Lu, 2007; Martinez et al., 2002; Avila et al., 2002).

In parallel to the findings of present study, previously Camkerten et al. (2009) and Beigh et al. (2016) reported that the oxidant/antioxidant balance is shifted towards oxidative in dogs with sarcoptic mange. Further, Behera et al. (2011) reported significantly elevated parameters of oxidative stress get normalize with ivermectin + vitamin E-selenium treated group, but not in ivermectin treated group, in sarcoptic mange of dogs.

\section{Parasitological cure efficacy}

Microscopic examination of skin scrapings of dogs with CSA revealed presence of high numbers of eggs, developing stages and adult mites per microscopic field before start of the therapy. Sarcoptes-infested dogs were examined for skin scrapping on days 0,14 and 28 of the study. The parasitological cure rate was calculated as the proportion of dogs negative for $S$. scabiei mites on the basis of microscopic examination of deep skin scrapings obtained on day 14 and 28 post therapy. In Sarcoptesinfested dogs, the parasitological cure rate on day 14 was $40 \%$ in both the treatment groups. A $100 \%$ parasitological cure rate was noticed in both the treatment groups at day 28 post therapy. The numbers of dogs parasitologically cured from Sarcoptes infestation on various days of therapy are depicted in Table 6.

Table 6: Parasitological cure efficacy of various days of therapy in various groups of dogs suffering from Canine Sarcoptic Acariasis

\begin{tabular}{llll}
\hline \multicolumn{4}{c}{ Parasitological cure efficacy of various days of therapy } \\
\hline Groups & Day 0 & Day $\mathbf{1 4}$ & Day $\mathbf{2 8}$ \\
\hline $\mathbf{1}$ & $0 / 5$ & $2 / 5(40 \%)$ & $5 / 5(100 \%)$ \\
$\mathbf{2}$ & $0 / 5$ & $2 / 5(40 \%)$ & $5 / 5(100 \%)$ \\
\hline
\end{tabular}

\section{Clinical cure efficacy}

Pro-inflammatory cytokine production appears to be the effector key in the pathogenesis of scabies (Walton et al., 2008). These cytokines can also be generated from the inflammation of the skin itself caused by physical stimulation of the burrowing mites (Portugal et al., 2007). Triggering of this pro-inflammatory cascade lead to excessive generation of the reactive oxidants, free radicals which include reactive oxygen species (ROS) such as hydroperoxide radical $(\mathrm{OH})$, superoxide anion radical $\left(\mathrm{O}_{2}\right)$ and reactive nitrogen species (RNS) such as nitric oxide radical (NO) in the biological system (Bickers and Athar, 2006). Free radicals induce or contribute to adverse effects on the skin, including edema, erythema, wrinkling, inflammation, autoimmune reaction, hypersensitivity and keratinization abnormalities (Bickers and Athar, 2006). ROS, in addition to imparting oxidative insult by damaging structural and functional components of cellular systems, is also able to induce apoptosis (Sarafian and Bredesen, 1994; Czaja, 2002). Sarcoptes-induced skin lesion score (SSLS) and clinical recovery score analysis (\% improvements in SSLS) of various days of therapy in 
Table 7: Sarcoptes-induced Skin Lesion Score (SSLS) and (\%) Improvement SSLS in various groups of dogs suffering from Canine Sarcoptic Acariasis

\begin{tabular}{llllll}
\hline \multirow{2}{*}{ Groups } & \multicolumn{3}{c}{ Sarcoptes-induced Skin Lesion Score (SSLS) } & \multicolumn{2}{c}{ (\%) Improvement SSLS } \\
\cline { 2 - 6 } & DAY 0 & DAY 14 & DAY 28 & DAY 14 & DAY 28 \\
\hline 1 & $15.48 \pm 0.47^{\mathrm{C}}$ & $9.20 \pm 0.24^{\mathrm{bB}}$ & $5.88 \pm 0.20^{\mathrm{bA}}$ & $40.37 \pm 1.93^{\mathrm{aA}}$ & $61.84 \pm 1.66^{\mathrm{aB}}$ \\
2 & $15.73 \pm 0.64^{\mathrm{C}}$ & $4.80 \pm 0.32^{\mathrm{aB}}$ & $1.46 \pm 0.11^{\mathrm{aA}}$ & $69.50 \pm 1.47^{\mathrm{bA}}$ & $90.68 \pm 0.57^{\mathrm{bB}}$ \\
\hline
\end{tabular}

Mean with different superscript (a, b) in columns are differing significantly in between the groups, otherwise non-significant.

Mean with different superscript (A, B) in rows are differing significantly in between the intervals, otherwise non-significant.

various groups of dogs suffering from Canine Sarcoptic Acariasis are depicted in Table 7.

In the present study group 2 revealed significantly better $\%$ improvement in SSLS at day 14 and 28 post therapy compared to group 1 at similar days. The difference in rates of clinical recovery from sarcoptic mange in treated groups could be attributed to the ameliorative/antioxidant effect of SAMe which enhances immune system, and neutralizes damaging elements called free radicals. Several studies have demonstrated that SAMe can alleviate signs of oxidative and nitrosative stress (Lieber, 2002; Hanje et al., 2006).

\section{CONCLUSION}

On the basis of findings of present investigation, it is concluded that Sarcoptes scabiei infestation induces alterations in various biochemical parameters in dogs and lead to a state of significant oxidant-antioxidant imbalance. Administration of SAMe in addition to standard therapy can mitigate these alterations expediting the clinical recovery of diseased dogs and therefore can be recommended as an adjunct therapy with miticides for management of canine sarcoptic mange.

\section{ACKNOWLEDGMENTS}

Authors are thankful to the Dean, COVSc and Dean PGS, DUVASU, Mathura for providing necessary facilities to carry out the study.

\section{REFERENCES}

Allaam, M.A., Allam, T.S. and Elkhatam, A.O. 2014. Biochemical and circulating oxidative stress biomarkers in Egyptian buffaloes (Bubalus bubalis) infested by sarcoptic mange. Glob. Vet., 13(4): 656-661.
Anita, P. and Peter, F. 2008. Saunders Solutions in Veterinary Practice - Small Animal Dermatology. $1^{\text {st }}$ Ed., Elsevier Ltd.

Ara, A.I., Xia, M., Ramani, K., Mato, J.M. and Lu, S.C. 2008. S-adenosylmethionine inhibits lipopolysaccharide induced gene expression via modulation of histone methylation. Hepatol., 47: 1655-66.

Arlian, L.G., Morgan, M.S. and Neal, J.S. 2003. Modulation of cytokine expression inhuman keratinocytes and fibroblasts by extracts of scabies mites. Am. J. Trop. Med. Hyg., 69: $652-656$

Avila, M.A., Garcia-Trevijano, E.R., Martinez-Chantar, M.L., Latasa, M.U., Pérez-Mato, I., Martínez-Cruz, L.A., del Pino, M.M., Corrales, F.J. and Mato, J.M. 2002. S-adenosylmethionine revisited: its essential role in the regulation of liver function. Alcohol., 27: 163-167.

Bargaglia, E., Olivieria, C., Bennetta, D., Prasseb, A., MullerQuernheimb, J. and Rottolia, P. 2009. Oxidative stress in the pathogenesis of diffuse lung diseases: A review. Respir Med., 103(9): 1245-1256.

Behera, S.K., Dimri, U., Singh, S.K. and Mohanta, R.K. 2011. The curative and antioxidative efficiency of ivermectin and ivermectin + vitamin E-selenium treatment on canine Sarcoptes scabiei infestation. Vet. Res. Comm., 35: 237-244.

Beigh, S.A., Soodan, J.S., Bhat and A.M. 2016. Sarcoptic mange in dogs: Its effect on liver, oxidative stress, trace minerals and vitamins. Vet. Parasitol., 227: 30-34.

Beigh, S.A., Soodan, J.S., Singh, R. and Khan, A.M. 2013. Trace minerals status and antioxidative enzyme activity in dogs with generalized demodicosis. Vet. Parasitol., 198: 180-186.

Benjamin, M.M. 1978. Outline of veterinary clinical, pathology, $3^{\text {rd }}$ Ed. Iowa state Uni. Press., Ames; pp. 27-273 and 286-291.

Bickers, D.R. and Athar, M. 2006. Oxidative stress in the pathogenesis of skin disease. J. Invest. Dermatol., 126(12): $2565-2575$.

Bornstein, S., Mörner, T. and Samuel, W.M. 2001. Sarcoptes scabiei and sarcoptic mange. In: Samuel WM, Pybus MJ, Kocan AA (eds) Parasitic diseases of wild mammals, $2^{\text {nd }}$ Ed. Iowa State University Press, Ames, pp. 107-119. 
Bourdeau, P., Armando, L. and Marchand, A. 2004. Clinical and epidemiological characteristics of 153 cases of sarcoptic acariosis in dogs. Vet. Dermatol., 15: 48.

Camkerten, I., Sahin, T., Borazan, G., Gokcen, A. and Das, A. 2009. Evaluation of blood oxidant/antioxidant balance in dogs with sarcoptic mange. Vet. Parasitol., 161: 106-109.

Cargil, C.F. and Dobson, K.J. 1977. Field and experimental studies of sarcoptic mange in pigs in South Australia. Proc $54^{\text {th }}$ Proceedings of the Annual Conference of the Australian Veterinary Association, pp. 129.

Chandy, J., Nambi, A.P., Jeyaraja, K. and Gowri, B. 2000. Clinicopathological and biochemical studies in scabies in dogs. Indian Vet J., 77: 755-757.

Czaja, M.J. 2002. Induction and regulation of hepatocyte apoptosis by oxidative stress. Antioxid. Redox Signal., 4: 759-767.

De, U.K. and Dey, S. 2010. Evaluation of organ function and oxidant/antioxidant status in goats with sarcoptic mange. Trop Anim Health Prod., 42(8): 1663-1668.

Ewans, P. and Halliwell, B. 2001. Micronutrients: oxidant/ antioxidant status. Br. J. Nutr., 85:67-74.

Fang, Y.Z., Yang, S. and Wu, G. 2002. Free radicals, antioxidants and nutrition. Nutrition., 18: 872-879.

Finkel, T. and Holbrook, N.J. 2000. Oxidants, oxidative stress and the biology of ageing. Nature. 408: 239-47.

Goudie, A.C., Evans, N.A., Gration, K.A.F., Bishop, B.F., Gibson, S.P., Holdom, K.S., Kaye, B., Wicks, S.R., Lewis, D., Weatherley, A.J., Bruce, C.I., Herbert, A. and Seymour, D.J. 1993. Doramectin - a potent novel endectocide. Vet. Parasitol., 49: 5-15.

Griffin, C.E. 1993. Current Veterinary Dermatology. The Science and Art of Therapy, Eds Griffin, Kwochka \& MacDonald, StLouis, Mosby-Year Book; p.85.

Halliwell, B. 2006. Reactive species and antioxidants. Redox biology is a fundamental theme of aerobic life. Plant Physiol., 141(2): 312-322.

Hanje, A.J., Fortune, B., Song, M., Hill, D. and McClain, C. 2006. The use of selected nutrition supplements and complementary and alternative medicine in liver disease. Nutr. Clin. Pract., 21: 255-72.

Hennessy, D.R. and Alvinerie, M.R. 2002. Pharmacokinetics of the macrocyclic lactones: Conventional wisdom and new paradigms. Macrocyclic Lactones in Antiparasitic Therapy. J. Vercruysee and R.S. Rew. Wallingford, UK, CABI Publishing. 97-123.

Hicks, M. and Elston, D. 2009. Scabies. Dermatol Ther, 22: 279-292.
Hirudkar, U.S., Desphande, P.D., Narladkar, B.W. and Vadlamudi, V.P. 1997. Effect of herbal treatment with Himax ointment and Neem oil in sarcoptic mange in sheep. Indian Vet. J., 74: 506

Kocyigit, A., Keles, H., Selek, S., Guzel, S., Celik, H. and Erel, O. 2005. Increased DNA damage and oxidative stress in patients with cutaneous leishmaniasis. Mutat. Res., 585: 71-78.

Krieger, K., Heine, J., Dumont, P. and Hellmann, K. 2005. Efficacy and safety of imidacloprid $10 \%$ plus moxidectin $2.5 \%$ spot-on in the treatment of sarcoptic mange and otoacariosis in dogs: results of a European field study. Parasitol. Res., 97: 81-88.

Lieber, C.S. 2002. S-adenosyl-L-methionine: its role in the treatment of liver disorders. Am. J. Clin. Nutr., 76: 1183S-7S.

Lodh, C., Chakrabarti, A. and Santra, S. 2012. Scabies in dogs and its haematobiochemical changes. Indian J. Canine Pract., 4(2): 102-104.

Logan, N.B., Weatherley, A.J., Philiphs, F.E., Wilkins, C.P. and Shanks, D.J. 1993. Spectrum of activity of doramectin against cattle mites and lice. Vet. Parasitol., 49: 67-73.

Martinez-Chantar, M.L., Garcia-Trevijano, E.R., Latasa, M.U., Pérez-Mato, I., Sánchez del Pino, M.M., Corrales, F.J., Avila, M.A. and Mato, J.M. 2002. Importance of a deficiency in S-adenosyl-L methionine synthesis in the pathogenesis of liver injury. Am. J. Clin. Nutr., 76: 1177S-82S.

Mato, J.M. and Lu, S.C. 2007. Role of S-adenosyl-L-methionine in liver health and injury. Hepatol., 45: 1306-12.

Mueller, R.S., Bettenay, S.V. and Shipstone, M. 2001. Value of the pinnal-pedal reflex in the diagnosis of canine scabies. Vet. Rec., 148: 621.

Mullins, J.S., Arlian, L.G. and Morgan, M.S. 2009. Extracts of Sarcoptes scabiei De Geer down modulate secretion of IL-8 by skin keratinocytes and fibroblasts and of GM-CSF by fibroblasts in presence of proinflammatory cytokines. J. Med. Entomol., 46: 845-851.

Narang, A., Krishan, G. and Arora, N. 2015. Sarcoptic Mange infestation in a dog - treatment using ivermectin pour-on. Ann. Vet. Anim. Sci., 3(2): 59-61.

Nemec, A., Brobnic-Kosorok, M., Skitek, M., Pavlica, Z., Galac, S. and Butinar, J. 2000. Total antioxidant capacity (TAC) values and their correlation with individual antioxidants in serum of healthy beagles. Acta Vet. Brno., 69: 297-303.

Noviana, D., Harjanti, D., Otsuka, Y. and Horii, Y. 2004. Proliferation of protease-enriched mass cell in sarcoptic skin lesions of raccoon dogs. J. Comp. Pathol., 131: 28-37.

Pence, D.B. and Ueckermann, E. 2002. Sarcoptic manage in wildlife. Rev. Sci. Tech., 21: 385-398. 
Pin, D., Bensignor, E., Carlotti, D.N. and Cadiergues, M.C. 2006. Localised sarcoptic mange in dogs: a retrospective study of 10 cases. J. Small Anim. Pract., 47: 611-614.

Portugal, M., Barak, V., Ginsburg, I. and Kohen, R. 2007. Interplay among oxidants, antioxidants and cytokines in skin disorders: present status and future considerations. Biomed. Pharmacother, 61: 412-422.

Ranjan, R., Naresh, R., Patra, R.C. and Swarup, D. 2006. Erythrocyte lipid peroxides and blood zinc and copper concentrations in acute undifferentiated diarrhoea in calves. Vet. Res. Commun., 30: 249-254.

Ranjan, R., Swarup, D., Naresh, R. and Patra, R.C. 2005. Enhanced erythrocytic lipid peroxides and reduced plasma ascorbic acid and alteration in blood trace elements level in dairy cows with mastitis. Vet. Res. Comm., 29: 27-34.

Reddy, B.S., Kumari, K.N. and Sivajothi, S. 2014. Thyroxin Levels and Haematological changes in Dogs with Sarcoptic Mange. J Adv. Parasitol., 1(2): 27-29.

Reinmeyer, C.R. and Courteny, C.H. 2001. Antinematodal drugs. In: Adams HR ed. Veterinary Pharmacology and Therapeutics. Ames, Iowa: State University Press, pp. 94779.

Sakina, A. and Mandial, R.K. 2013. Hematobiochemical Changes in Canine Scabies. Vetscan., 123, 7(2): 27-30.

Saleh, M.A., Mahran, M.O. and AlSalahy, B.M. 2010. Circulating oxidative stress in dromedary camels infested with sarcoptic mange. Vet. Res. Comm., 35: 35-45.

Santra, A., Maiti, A., Chowdhury, A. and Mazumder, D.N. 2000. Oxidative stress in liver of mice exposed to arsenic contaminated water. Indian J Gastroenterol., 19: 152-155.

Sarafian, T.A. and Bredesen, D. E. 1994. Is apoptosis mediated by reactive oxygen species? Free Radic. Res., 21: 1-8.

Sharma, S.K., Soodan, J.S., Bal, M.S., Khajuria, J.K. and Upadhyay, S.R. 2009. Parasitic dermatitis in canines of Jammu region. J. Vet. Parasitol., 23(1): 65-67.

Sharma, S.K., Soodan, J.S. and Sharma, N. 2011. Haematobiochemical alterations in canine dermatitis. Indian Vet. J., 88(4): 56-58.
Sharma, S.K. 2006. Etiology haematobiochemical and therapeutics of skin diseases in canine. M.V.Sc. thesis Sher-EKashmir University of Agril. Sciences and Techonology, Jammu (J\&K), India.

Solanki, J.B., Hasnani, J.J., Patel, D.M., Patel, P.V. and Raval, S.K. 2007. Canine demodicosis in Anand. J. Vet. Parasitol., 21(1): 79-80.

Thurman, R.G., Bradford, B.U., Iimuro, Y., Frankenberg, M.V., Knecht, K.T., Connor, H.D., Adachi, Y., Wall, C., Arteel, G.E., Raleigh, J.A., Forman, D.T. and Mason, R.P. 1999. Mechanisms of alcohol-induced hepatotoxicity studies in rats. Front. Biosci., 4: 42-46.

Tilley, L.P. and Smith, F.W.K. 2007. Blackwell's Five-Minute Veterinary Consult Canine and Feline. $4^{\text {th }}$ Ed., pp. 1226.

Trenam, C.W., Blake, D.R. and Morris, C.J. 1992. Skin inflammation: reactive oxygen species and the role of iron. $J$. Invest. Dermatol., 99: 675-82.

Trouba, K., Hamadeh, H., Amin, R. and Germolec, D. 2002. Oxidative stress and its role in skin disease. Antioxid Redox Signal., 4: 665-673.

Valko, M., Leibfritz, D., Moncol, J., Cronin, M.T., Mazur, M. and Telser, J. 2007. Free radicals and antioxidants in normal physiological functions and human disease. Int. $J$. Biochem. Cell Biol., 39: 44-84.

Walton, S.F., Beroukas, D., Roberts-Thomson, P. and Currie, B.J. 2008. New insights into disease pathogenesis in crusted (Norwegian) scabies: the skin immune response in crusted scabies. Br. J. Dermatol., 158: 1247-1255.

Webster, C.R.L. and Cooper, J. 2009. Therapeutic Use of Cytoprotective Agents in Canine and Feline Hepatobiliary Disease. Vet. Clin. North Am. Small Anim. Pract., 39: 631652.

Willis, C., Fischer, K., Walton, S.F., Currie, B.J. and Kemp, D.J. 2006. Scabies mite inactivated serine protease paralogues are present both internally in the mite gut and externally in feces. Am. J. Trop. Med. Hyg., 75: 683-687.

Yathiraj, S., Rao, P.M., Reddy, N.R.J. and Rai, M.T. 1990. Treatment of scabies in canines with amitraz. Indian Vet. J., 67: 867-868. 